\title{
Non-steroidal anti-inflammatory drugs: overall risks and management. Complementary roles for COX-2 inhibitors and proton pump inhibitors
}

\author{
C J Hawkey, M J S Langman
}

Gut 2003;52:600-608

Non-steroidal anti-inflammatory drugs (NSAIDs) are well recognised as causing peptic ulceration and ulcer complications. However, several critical issues, including the amount of both gastrointestinal and non-gastrointestinal disease affected by NSAIDs, their interaction with ancillary risk factors, and how to optimise management in subgroups, remain poorly understood. In this article, strategies for subgroups that take account of non-specific gastrointestinal risks, minimisation of residual risk, and the importance of non-gastrointestinal toxicity are suggested, and areas for research identified.

See end of article for authors' affiliations

Correspondence to: Professor C J Hawkey, Division of

Gastroenterology, Queen's Medical Centre, University

Hospital Nottingham, Nottingham NG7 2UH,

UK; cj.hawkey@

nottingham.ac.uk

Accepted for publication 3 September 2002

\section{SUMMARY}

The gastrointestinal consequences of nonsteroidal anti-inflammatory drugs (NSAIDs) are the best recognised iatrogenic problem in clinical medicine. Although considerable, these gastrointestinal problems are overestimated in many studies, partly because association and cause are not always distinguished. An attributable rate of hospitalisation greater than 1 per 100 patient years is unlikely, even in patients over 60 years of age. Conversely, non- gastrointestinal adverse events, including fluid retention and its consequences, have until recently been relatively neglected. Selective inhibitors of the inducible cyclooxygenase (COX)-2 enzyme are important new therapies which, by sparing COX-1, undoubtedly reduce the risk of upper gastrointestinal bleeding caused by NSAIDs, and may abolish it, leading to extremely low event rates in patients without other risk factors. Recommendations to use COX-2 inhibitors in high risk patients unduly discounts this ability to minimise residual risk in low risk patients and may be misplaced if the potential of proton pump inhibitor (PPI) prophylaxis to reduce non-specific as well as NSAID specific risk is shown to lead to lower overall event rates in such individuals. In this article, strategies for subgroups that take account of non-specific gastrointestinal risks, minimisation of residual risk, and the importance of non-gastrointestinal toxicity are suggested, and areas for research identified. The possibility that ibuprofen $\leqslant 1200 \mathrm{mg}$ daily may offer comparable overall safety, especially when combined with a PPI for defined patients, warrants formal evaluation. The extent and nature of NSAID or COX-2 inhibitor interactions with aspirin in influencing both cardiovascular and gastrointestinal outcomes needs clarifying.

\section{INTRODUCTION}

Non-steroidal anti-inflammatory drugs (NSAIDs) are well recognised as causing peptic ulceration and ulcer complications. The advent of effective protective therapies, such as co- prescription of misoprostol or PPIs or use of safer NSAIDs, including COX-2 inhibitors, makes this information of practical importance. However, several critical issues, including the amount of both gastrointestinal and non-gastrointestinal disease affected by NSAIDs, their interaction with ancillary risk factors, and how to optimise management in subgroups, remain poorly understood. No protective strategy has yet demonstrated an overall reduction in death or critical life threatening event rates. To achieve this may require application of different approaches, taking account of all toxicities, to different subgroups of patients. In this article, we will try to provide best evidence assessment of the risks of NSAIDs and the net benefits of protective strategies, both overall and in subgroups, in an attempt to define strategies that could lead to net health benefit.

\section{AMOUNT OF GASTROINTESTINAL DISEASE ATTRIBUTABLE TO NSAID USE} Estimates from epidemiological studies

Estimates of the amount of disease attributable to NSAIDs have varied widely. This may be because distinctions are not made between causal and non-causal associations or because estimates based on events observed in high risk populations are assumed to apply generally. Bleeding accounts for most serious ulcer pathology. Based on a widely quoted population study, ${ }^{1}$ it can be estimated that there are 8528 hospitalisations for gastric and duodenal ulcer bleeding per annum in the UK. ${ }^{2}$ Based on estimates that between $20 \%$ and $25 \%$ are causally associated with intake of non-aspirin NSAIDs, and approximately 10\% more with aspirin used for cardiovascular prophylaxis, these figures suggest that (aspirin and nonaspirin) NSAIDs cause approximately 3500 hospitalisations for and 400 deaths from ulcer bleeding per annum in the UK in those aged 60 years and above. $^{2}$

Abbreviations: NSAIDs, non-steroidal anti-inflammatory drugs; COX, cyclooxygenase; PPI, proton pump inhibitor; NNT, number needed to treat. 
Table 1 Estimated rates of hospitalisation and death from non-steroidal anti-inflammatory drug (NSAID) attributable gastrointestinal disorders

\begin{tabular}{|c|c|c|c|c|c|}
\hline \multirow[b]{2}{*}{ Population } & \multirow{2}{*}{$\begin{array}{l}\text { End } \\
\text { point }\end{array}$} & \multirow{2}{*}{$\begin{array}{l}\text { Age } \\
\text { group (y) }\end{array}$} & \multicolumn{2}{|c|}{$\begin{array}{l}\text { Estimated annual attributable rate of } \\
\mathrm{Gl}\end{array}$} & \multirow[b]{2}{*}{ Ref } \\
\hline & & & Hospitalisation & Death & \\
\hline 6 UK towns & UGIB & $60+$ & $0.23 \%$ & $0.027 \%$ & Lewis $^{69}$ \\
\hline Nottingham, UK & UGIB & $60+$ & $0.4 \%$ & NA & Hawkey $^{3}$ \\
\hline Tennessee Medicaid population & All GI & $60+$ & $1.25 \%$ & NA & Smalley ${ }^{6}$ \\
\hline VIGOR study population & All GI & $50+*$ & $0.7 \%$ & NA & Bombardier ${ }^{11}$ \\
\hline \multicolumn{6}{|c|}{$\begin{array}{l}\text { See text for calculations; death rates from UK mortality statistics are based on an assumption of } 1.5 \text { million } \\
\text { elderly NSAID users. } \\
\text { The VIGOR trial data show the difference in hospitalisation for gastrointestinal problems between patients } \\
\text { taking rofecoxib and those taking naproxen. } \\
\text { * } 40+\text { if using corticosteroids. } \\
\text { GI, gastrointestinal; UGIB, upper gastrointestinal bleeding. }\end{array}$} \\
\hline
\end{tabular}

"NSAIDs cause approximately 3500 hospitalisations for and 400 deaths from ulcer bleeding per annum in the UK in those aged 60 years and above"

There are approximately 10 million people aged 60 years and over in the UK and about 15\% (1.5 million) take NSAIDs at any time, thus implying an annual attributable rate of hospitalisation of $0.23 \%$ and of death of $0.027 \%$ for NSAID induced ulcer bleeding (table 1). Another population based study estimated that one episode of ulcer bleeding attributable to NSAIDs occurred in the elderly per 2828 prescriptions, implying that just over 4000 hospitalisations per annum are causally related, based on 12 million NSAID prescriptions per annum in the elderly. If one prescription is taken to last one month, a rate of ulcer bleeding of $0.4 / 100$ patient years in the elderly can be deduced (table 1).

Mortality statistics within the UK attribute just under 3500 gastric and duodenal ulcer deaths per annum in those over 60 years to peptic ulcer and its complications of all types. ${ }^{4}$ If $20-25 \%$ are due to non-aspirin NSAIDs, the implied death rate due to these drugs is between 700 and 900 per annum. This is somewhat higher than estimates from population based studies but includes perforation, sudden death with bleeding in the community, and any oesophageal ulcer deaths attributable to NSAIDs. Overall, it seems that NSAID induced ulceration may cause no more than 1000 deaths per annum in the UK and that quoted event rates of $1-4 \%$ per annum and theoretical calculations of 2000 deaths per annum ${ }^{5}$ are overestimates.

For reasons that are unclear, higher estimates come from the USA where 1.25 excess gastrointestinal hospitalisations per 100 patient years has been calculated for NSAID users in the Tennessee Medicaid Program (table 1). ${ }^{6}$ One reason could be that patients are more readily admitted for ulcer associated events with a lower mortality in the USA than in the UK. However, there is no direct evidence that this is so, and UK figures applied pro rata would imply no more than 5000 deaths caused per annum in the USA while "conservative estimates" of "at least 16500 " NSAID associated deaths have been calculated..$^{78}$ It is difficult to believe that these estimates are in fact conservative, even allowing for high rates of non-causal association, as only 6500 deaths per annum are recorded with peptic ulcer as the primary cause, and another 11000 where it has been the secondary diagnosis. ${ }^{90}$

\section{Estimates from clinical trials}

Three large cohort studies have been fairly consistent in estimating the total risk of hospitalisation for gastrointestinal complications associated with NSAID use as between 1.3 and 2.2 events per 1000 patient years. However, not all of these NSAID associated events are caused by NSAIDs. Differences in rates of hospitalisation for patients on NSAIDs compared with coxibs may approximate to those caused by NSAIDs if coxibs do not cause ulcers. In the VIGOR study, this excess was 0.7 events per 100 patient years (table 1). ${ }^{11}$ Values from CLASS ${ }^{12}$ are of a similar magnitude but less informative because of concomitant aspirin use and uncertainty about the status of the published data which encompass only part of the study. ${ }^{13-15}$ Overall clinical trials, in populations both within and outside of the USA, yield estimates of risk that are quite similar to those from epidemiological studies from the UK.

\section{AMOUNT OF NON-GASTROINTESTINAL DISEASE ATTRIBUTABLE TO NSAID USE}

As well as their effects on the upper gastrointestinal tract, NSAIDs can also cause lower intestinal haemorrhage or perforation ${ }^{16}$ and may exacerbate colitis. ${ }^{17}$ In addition, common non-gastrointestinal adverse effects include the consequences of salt and water retention, renal failure, provocation of bronchospasm, and hypersensitivity reactions. Of these, the propensity of non-selective and selective NSAIDs to induce salt and water retention has received increasing attention, ${ }^{18-22}$ as has speculation about antiplatelet effects. ${ }^{23}$

\section{Salt and water retention}

Although NSAIDs affect renal blood flow, their most consistent effect is in enhancing renal sodium reabsorption as a result of cyclooxygenase (largely COX-2) inhibition predisposing to hypertension and oedema. ${ }^{20}$ Large meta-analyses suggest that NSAID treatment elevates blood pressure by an average of 3-5 mm Hg (fig 1 ). ${ }^{25}{ }^{26}$ The Framingham studies and others examining the annual risk of cardiovascular events suggest that these increase in a linear fashion by approximately 4/1000 per $5 \mathrm{~mm} \mathrm{Hg}$ rise in blood pressure, ${ }^{27}$ implying a substantial effect of NSAIDs, which is supported by a case control study of patients admitted with heart failure..$^{28}$ Applied to the 1.5 million NSAID users aged 60 years and over in the UK, these figures would suggest that NSAIDs might cause as much cardiovascular disease as a consequence of drug induced hypertension as they do ulcer complications.

\section{Effect of aspirin and non-aspirin NSAIDs on thrombotic} complications of vascular disease

As a result of prolonged profound irreversible inhibition of platelet thromboxane, aspirin is well recognised as reducing thrombotic complications of vascular disease. ${ }^{29}{ }^{30}$ Non- aspirin NSAIDs also inhibit platelet thromboxane, usually less potently, reversibly, and for a shorter time than aspirin. ${ }^{24}$ NSAIDs also inhibit vascular prostacyclin synthesis, making it difficult to predict what effect they would have on thrombosis. ${ }^{18}{ }^{31}$ Results of studies on the relationship between NSAIDs and myocardial infarction conflict, ${ }^{32-39}$ but it seems that any overall effect of NSAIDs on thrombotic disease may at best be small. This net effect could arise because NSAIDs generally have insufficient antiplatelet activity to prevent coronary thrombosis or because limited antithrombotic activity 


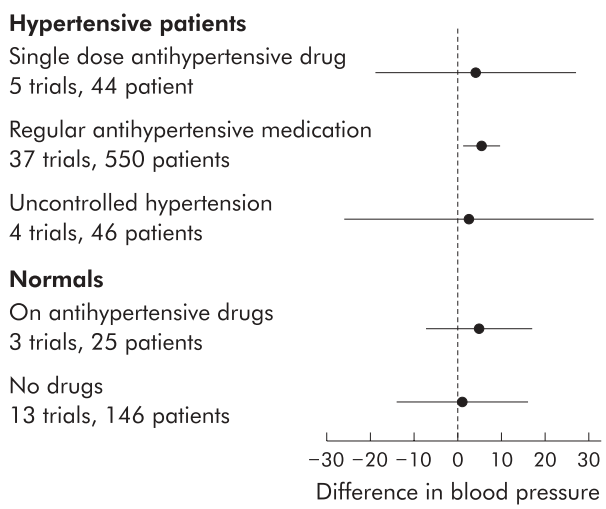

Figure 1 Effects of non-steroidal anti-inflammatory drugs on blood pressure (relative risk and 95\% confidence intervals), based on Johnson and colleagues ${ }^{25}$ (reproduced with permission). The largest body of data concern hypertensive patients.

counterbalances adverse effects on vascular prostacyclin and blood pressure.

\section{Interactions between aspirin and non-aspirin NSAIDs}

Potentially more important is the recent report that ibuprofen, and possibly other NSAIDs, can abolish the ability of aspirin to inhibit platelet aggregation. ${ }^{40}$ Mechanistically this may arise because ibuprofen binds (reversibly) to platelet cyclooxygenase long enough to impede access of aspirin to the site that it normally acetylates, to inhibit platelet cyclooxygenase irreversibly (fig 2). Because a substantial number of patients take both aspirin and NSAIDs, it will be important to test directly the implication of this pharmacodynamic study, that patients might lose the cardioprotective effects of aspirin when taking at least some NSAIDs.

\section{PROTECTIVE STRATEGIES}

These concern either co-prescription of a protective drug such as misoprostol or a PPI, or substitution of a drug with reduced toxicity. Previously, paracetamol and ibuprofen were regarded as the safer drugs for consideration ${ }^{41}$ but recent attention has highlighted COX-2 selective inhibitors that combine high potency with substantial gastrointestinal safety.

\section{COX-2 INHIBITORS}

Many have focused on the question of who should receive selective COX-2 inhibitors in preference to non-selective NSAIDs. Consensus statements have consistently recommended that selective COX-2 inhibitors should be used in patients with high but not low risks of gastrointestinal complications. ${ }^{42-44}$ However, whether this is appropriate depends on how different is the overall safety of selective and non-selective agents, the degree to which high risk patients contribute to the overall burden of NSAID induced gastrointestinal complications, and the extent to which their increased risk is NSAID specific as opposed to a general risk that would still continue to apply without NSAIDs.

\section{Impact of COX-2 inhibitors on gastrointestinal disease}

In 3-6 month endoscopy studies, the selective COX-2 inhibitors rofecoxib and celecoxib have been associated with a fourfold reduction in ulcers detected by endoscopy, even at high dose, by comparison with normal doses of standard NSAIDs. ${ }^{40-50}$ Broadly similar results have been seen with newer COX-2 inhibitors. ${ }^{51}{ }^{52}$ High doses of rofecoxib and celecoxib have been subject to large scale prospective outcomes studies. In the VIGOR study, clinically significant ulcers were reduced by $54 \%$ and ulcer complications by $57 \%$, a result compatible with estimates from large scale analysis of osteoarthritis trials. ${ }^{53}$
"Rofecoxib and celecoxib have been associated with a fourfold reduction in ulcers detected by endoscopy, even at high dose, by comparison with normal doses of standard NSAIDs"

Assessment of celecoxib is more complicated. Combined analysis of complications in endoscopic studies suggested substantial reductions, ${ }^{49}$ as did an initial publication of partial data from the CLASS study. ${ }^{12}$ The final negative result for the trial as a whole ${ }^{13-15}$ is likely to have arisen because of problems of trial design rather than lack of safety. Recent data suggest that the incidence of clinical lower gastrointestinal events is also reduced with COX-2 inhibitors ${ }^{54}$ (Laine et al 2002, Annals Intern Med (submitted)).

\section{Impact of COX-2 inhibitors on non-gastrointestinal disease}

Selective COX-2 inhibitors cause sodium and water retention, hypertension, and oedema, with effects broadly similar to those of non-selective NSAIDs when compared at equivalent doses. $^{18} 19212255$ Suggestions that celecoxib lacks these mechanism dependent effects ${ }^{56}$ seem likely to arise because of dose confounding and/or differences in absorption characteristics and half life.5

\section{Thrombotic complications of vascular disease}

The summary bases for approval of celecoxib and rofecoxib showed no increases in cardiovascular event rates in osteoarthritis patients (about 4000 patients for each drug). ${ }^{575}$ However, in the VIGOR study, patients receiving rofecoxib $50 \mathrm{mg}$ (a supratherapeutic dose) had a significantly higher rate of cardiovascular events than those receiving naproxen lg daily, ${ }^{11}$ an ad hoc finding whose uncertain significance has overshadowed the important gastrointestinal primary end point of the study. ${ }^{59}$ Plausible explanations include an antithrombotic effect of naproxen (which differs from other NSAIDs in consistently achieving platelet inhibition that is sufficiently prolonged and profound to be truly aspirin- like ${ }^{60}$ ), a prothrombotic effect of unopposed inhibition of prostacyclin derived from endothelial COX-2 by a supratherapeutic dose of rofecoxib, ${ }^{18}$ or susceptibility of rheumatoid arthritis patients to the adverse cardiovascular events of the drug. There are no firm data that distinguish these possibilities, although this has not inhibited a flurry of unjustifiable speculation $^{2359}$ and controversy. ${ }^{61}$ Some studies ${ }^{38}{ }^{39}$ support a protective effect of naproxen, others ${ }^{35}$ do not. No studies of normal (as opposed to supratherapeutic) doses of selective COX-2 inhibitors, including placebo comparisons, suggest that the rate of myocardial infarction is increased (fig 3). ${ }^{59}$ It will take time for the issues to be effectively addressed, for instance through comparison of cardiovascular adverse event rates in placebo controlled trials of COX selective NSAIDs in treating Alzheimer's disease or those at risk of gastrointestinal cancer.

\section{Interactions between COX-2 inhibitors and low dose aspirin}

The CLASS study is of interest because in the $21 \%$ of patients who took low (ish) doses of aspirin (325 mg or less) an advantage of reduced peptic ulcer rates for celecoxib was not demonstrable over its NSAID comparator. ${ }^{12}$ It is unclear whether what was found represents the play of chance, distortion by post hoc analysis, intrinsic toxicity of aspirin, or synergism between COX-1 and COX-2 inhibition. ${ }^{62}$ Parallel data on rofecoxib are not available. The small size of the dataset within CLASS should have deterred over-interpretation, but has not. Moreover, because of their selectivity, coxibs are unable to enter the platelet COX-1 channel, and rofecoxib appears to lack the ability of ibuprofen to interfere with the antiplatelet activity of aspirin, a mechanistic difference that could be advantageous. ${ }^{4063}$ 

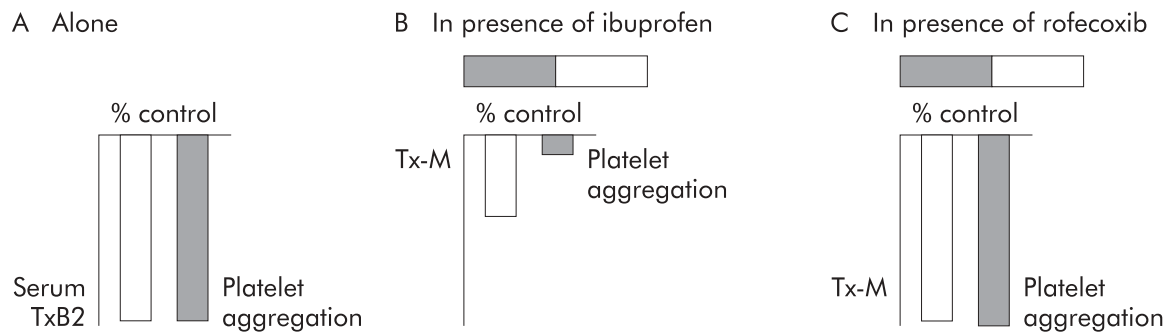

(i)

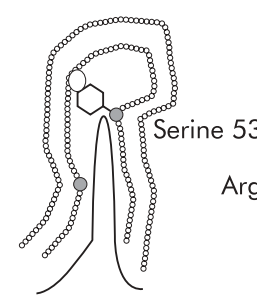

Aspirin

Arginine 530

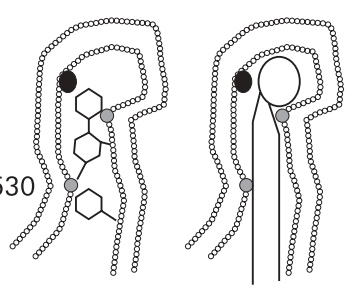

\&NAID (ii)

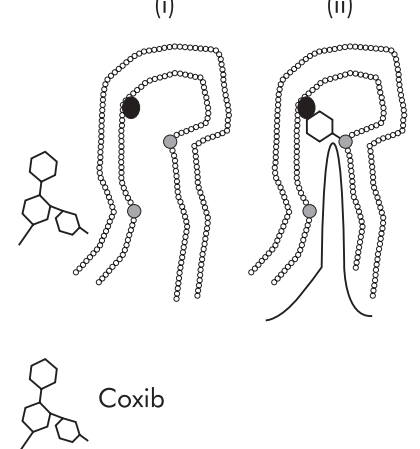

Figure 2 Interaction between aspirin, ibuprofen, and rofecoxib, based on Catella-Lawson and colleagues. ${ }^{63}$ (A) Aspirin $81 \mathrm{mg}$ reduces serum thromboxane ( $\mathrm{T} \times \mathrm{B} 2$ ) by $\geqslant 98 \%$ and platelet aggregation by $98 \%$ (at 24 hours). It does this by binding irreversibly to serine 530 and blocking entry of arachidonic acid (bottom panel). (B) When ibuprofen $400 \mathrm{mg}$ is given two hours before aspirin, serum thromboxane is only reduced by $53 \%$ at 24 hours and platelet aggregation is not affected, probably because ibuprofen, by reversibly binding to arginine 120, temporally impedes access of aspirin to serine 530 (bottom panel (i)). As a result, thromboxane can subsequently be synthesised allowing normal platelet aggregation (bottom panel (ii)). (C) After rofecoxib $25 \mathrm{mg}$, the effect of aspirin is unchanged. This may be because rofecoxib, because of its selectivity, means it does not access platelet cyclooxygenase and cannot impede aspirin in the same way as ibuprofen (bottom panel (i)). Consequently, aspirin can bind to serine 530 (bottom panel (ii)). NSAID, non-steroidal anti- inflammatory drug.

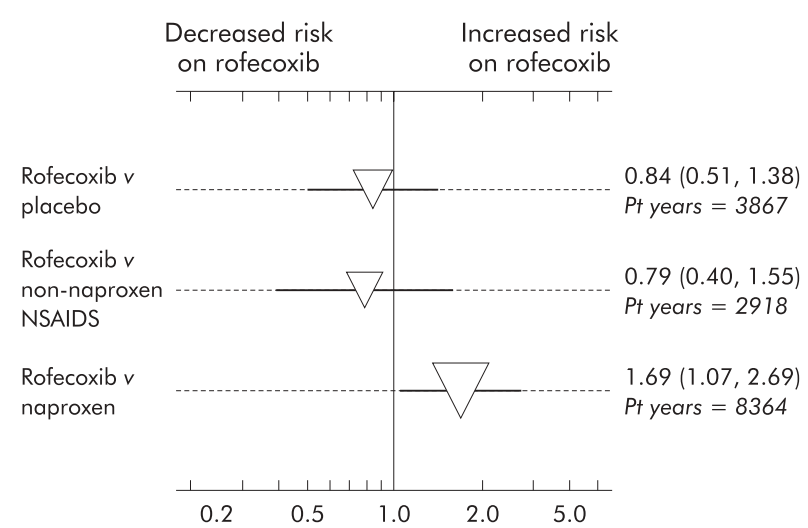

Figure 3 Vascular events on rofecoxib (relative risk and $95 \%$ confidence intervals) compared with placebo, non-naproxen non-steroidal anti-inflammatory drugs (NSAIDs), and naproxen, assessed by the Antiplatelet Trialists' Collaboration (APTC) end point (cardiovascular haemorrhagic and unknown death, non-fatal myocardial infarction, and non- fatal stroke). The increased rate seen in the VIGOR trial with rofecoxib $50 \mathrm{mg}$ compared with naproxen is not seen for therapeutic doses of rofecoxib compared with either placebo or other NSAIDs. Reproduced from Konstam and colleagues $^{59}$ with permission.

\section{ALTERNATIVES TO COX-2 SELECTIVE INHIBITORS}

An impressive aspect of the data on COX-2 inhibitors is that full and supratherapeutic doses have been shown to have less gastrointestinal toxicity than full doses of non-selective NSAIDs. It has not been proved that overall safety is increased, nor that gastrointestinal safety is better than lower doses of non-selective NSAIDs. As ibuprofen is commonly used at low doses $(\leqslant 1200 \mathrm{mg} /$ day), the data on COX-2 selective inhibitors need consideration in relation to the overall value of ibuprofen as well as paracetamol, both being generally considered relatively safe.

\section{Paracetamol}

Paracetamol has usually been regarded as safe within the gastrointestinal tract but it has demonstrable, although weak, ability to inhibit prostaglandin synthesis. ${ }^{64}{ }^{65} \mathrm{~A}$ well recognised association with ulcer complications was assumed to represent consumption in response to gut symptoms, ${ }^{66}$ an assumption supported by the temporal relationship between ingestion and ulcer bleeding. ${ }^{67}$

"Paracetamol has usually been regarded as safe within the gastrointestinal tract but it has demonstrable, although weak, ability to inhibit prostaglandin synthesis"

Recent data generated in an automated database has been used to suggest that paracetamol has dose dependent toxicity in the gut. ${ }^{68}$ These data are weakened by not including self purchased paracetamol, which accounts for most use, and the suggestion that paracetamol is harmful runs counter to other epidemiological evidence (table 2), ${ }^{66769}$ seems to have been generated as a byproduct of an examination of the safety of newer NSAIDs (where paucity of data prevented conclusions), and may yet have arisen because of confounding of drug use and indication for treatment. Nevertheless, although paracetamol is probably safer than NSAIDs, this is currently sub judice.

\section{LOWER TOXICITY NSAIDs}

Many epidemiological studies show that ibuprofen use is associated with a halving of ulcer complication rates compared with average expectation for NSAID users. ${ }^{41}$ This reflects relatively low potency and formulation that allows prescription of low doses, but the short half life of ibuprofen combined with its acidic nature can achieve selective trapping within joint ${ }^{70}{ }^{71}$ and so contribute additionally to a good efficacy to safety ratio. At doses of $\leqslant 1200 \mathrm{mg} /$ day, gastrointestinal 
Table 2 Dose dependent risks for paracetamol and selected non-steroidal anti-inflammatory drugs for upper gastrointestinal bleeding

\begin{tabular}{lcc}
\hline Variable & Daily dose $(\mathrm{mg})$ & \multicolumn{1}{c}{ OR $(95 \% \mathrm{Cl})$} \\
\hline Paracetamol & $<2000$ & $1.2(1.0,1.4)$ \\
& $2000-3999$ & $1.2(0.8,1.7)$ \\
Ibuprofen & $\geqslant 4000$ & $1.0(0.5,1,9)$ \\
& $<1200$ & $1.1(0.6,2.0)$ \\
& $1200-1799$ & $1.8(0.8,3.7)$ \\
Diclofenac & $\geqslant 1800$ & $4.6(0.9,22.3)$ \\
& $<75$ & $2.2(0.8,5.8)$ \\
Piroxicam & $75-149$ & $3.2(1.9,5.5)$ \\
& $\geqslant 150$ & $12.2(5.6,26.7)$ \\
& $\leqslant 10$ & $9.0(2.1,39.2)$ \\
& $11-20$ & $12.0(6.5,22.1)$ \\
& $\geqslant 21$ & $79.0(9.9,931.8)$ \\
\hline
\end{tabular}

OR $(95 \% \mathrm{Cl})$, odds ratio (95\% confidence interval).

Data are derived from Lewis and colleagues. ${ }^{69}$ They are based on reported doses used in the week before presentation, and are adjusted for use of aspirin, ketoprofen, anticoagulants, smoking, and past history of upper gastrointestinal problems.

risks may not be significantly increased above background (table 2), ${ }^{69}$ although this advantage is lost at higher doses.

Although a post hoc analysis of CLASS suggested diclofenac did not differ from celecoxib in risk ${ }^{58} 72$ epidemiological studies do not clearly support a separation from NSAIDs as a whole. ${ }^{41}$ As the effects of NSAIDs on sodium retention are dose dependant, low doses of ibuprofen may cause less hypertension and oedema. ${ }^{73}$ The reduction of risk during routine clinical use of ibuprofen is such that comparisons of safety (both gastrointestinal and non-gastrointestinal) and efficacy of reduced doses of ibuprofen $(\leqslant 1.2 \mathrm{~g}$ daily) with COX-2 inhibitors seem worth considering.

\section{Avoiding NSAIDs with more harmful gastrointestinal toxicity profiles}

Restricting prescribing of particularly toxic NSAIDs could achieve as much as encouraging choice of lower risk drugs. Use of azapropazone was restricted in the UK in 1994 because of observed toxicity, and a similar approach could be taken with other drugs perceived as being high risk. Although analysis of spontaneous adverse reaction reports suggested in the past that piroxicam did not differ materially from other NSAIDs in ulcerogenicity, ${ }^{74}$ there is consistent evidence from the UK and elsewhere that it is particularly likely to cause ulcer complications (table 2). ${ }^{41}{ }^{75}$ Unequivocal decisions about other drugs, such as ketoprofen, ${ }^{75}$ are hindered by widely varied assessments of toxicity, ${ }^{41}$ which may result from differing dose levels generally employed.

\section{CO-PRESCRIPTION OF GASTROPROTECTIVE DRUGS Misoprostol}

Much endoscopic evidence shows that misoprostol protects against gastroduodenal damage from NSAIDs. ${ }^{76}$ The clinical relevance of these findings is underpinned by the direct demonstration in the MUCOSA study that hospitalisation for ulcer complications was also reduced by $40 \% .^{77}$ Unfortunately, a high frequency of symptomatic adverse gastrointestinal events limits use of misoprostol.

\section{PPIs}

In endoscopic studies, PPIs are very effective in healing NSAID associated gastric and duodenal ulcers, and in preventing relapse. ${ }^{78-80}$ When used in patients continuing to take naproxen or aspirin after hospitalisation for ulcer bleeding, PPIs reduce later ulcer bleeding by 4-6-fold more compared with Helicobacter pylori eradication. ${ }^{81}{ }^{82}$ Limited endoscopic, but not outcome, data suggest similar protection in patients without initial ulcers. ${ }^{83} \mathrm{~A}$ weakness of PPIs is that they are unlikely to reduce lower gastrointestinal risks.

\section{Avoiding $\mathrm{H}_{2}$ receptor antagonists}

Normal doses of $\mathrm{H}_{2}$ antagonists do not effectively prevent NSAID induced gastric ulcers. ${ }^{85}$ Indeed, those on $\mathrm{H}_{2}$ antagonists have an increased rate of ulcer bleeding, possibly because of masking of warning symptoms. ${ }^{86}$ With falling cost of PPIs, there will be little justification for use of $\mathrm{H}_{2}$ antagonists, even for dyspepsia, in NSAID users.

\section{APPROACH TO MANAGEMENT OF SUBGROUPS Consensus statements and economics}

Five circumstances under which use of COX-2 selective inhibitors is recommended by the National Institute for Clinical Excellence (NICE) in the United Kingdom ${ }^{44}$ are: prolonged use of standard NSAIDs at maximum recommended doses; patients aged 65 years and over; patients with previous ulcer complications; patients whose co-medications (for example, corticosteroids, anticoagulants) increase the likelihood of upper gastrointestinal adverse events; and where there is serious comorbidity.

"Restrictions on use of selected COX-2 inhibitors arise because of their cost"

A broadly similar approach is taken by other consensus and guideline recommendations. ${ }^{42}{ }^{43}$ Restrictions on use of selected COX-2 inhibitors arise because of their cost. Similar considerations apply to PPIs, but a fall in price is likely to make a nonselective NSAID plus a PPI cheaper than a COX-2 inhibitor, making comparative judgements between the two strategies timely. Additionally, lower prices would make the combination of a PPI and a COX-2 inhibitor a cost effective strategy for very high risk patients as these are generally at risk even when not taking NSAIDs. $^{87}$

\section{OBTAINING OVERALL POPULATION BENEFIT: RISK REDUCTION AND RESIDUAL RISK}

Consensus methods applied to NSAID prescribing can, by focusing on high risk groups, result in strategies that reduce the number needed to treat (NNT) to achieve benefit. However, highly focused strategies leave large numbers of patients perceived as at lower risk unprotected and overall population benefit is small. Moreover, most of the accessory factors that raise risk in patients taking NSAIDs also do so in patients that do not use these drugs ${ }^{87}$ so that the continued impact of ancillary non-drug risk factors may still leave NSAID users at unacceptably high residual risk even when switched to safer alternatives. It follows that any satisfactory protective strategy must take account of overall risks in both users and non-users of NSAIDs and the reasons why some patients are at particular risk. Such strategies are likely to include the use of PPIs, and of low dose standard NSAIDs as well as of COX-2 inhibitors.

\section{Management of patients without ancillary risk factors}

Low risk patients are not generally considered as targets for use of selective COX-2 inhibitors. Yet from the point of view of residual risk, they are most logically the recipients of such treatment as their risk of ulcer disease, when using non-selective NSAIDs, in theory derives solely from such drug use, making it possible that low risk patients could become no risk patients. Trial data support this notion. In VIGOR, rates of ulceration in patients without specified risk were reduced by $88 \%$ from 1.9 (on naproxen) to 0.2 per 100 patient years on rofecoxib. In CLASS, comparable figures (six month data) were 1.35 per 100 patient years (non-selective NSAIDs) and 0.35 per 100 patient years (celecoxib). 


\section{"Epidemiological studies suggest that reducing NSAID doses reduces risk"}

Epidemiological studies suggest that reducing NSAID doses reduces risk ${ }^{41}{ }^{88}$ possibly to background levels with ibuprofen $\leqslant 1200 \mathrm{mg} /$ day. ${ }^{69}$ It therefore follows that direct comparison of low dose ibuprofen and a COX-2 inhibitor for safety and efficacy in this group of patients would be worthwhile if the size were not to daunting.

\section{MANAGEMENT OF PATIENTS WITH ANCILLARY RISK FACTORS}

For many high risk patients an all embracing preventive strategy is logically more appropriate by reason of the influence of non-NSAID related risk factors.

\section{Past ulcer history}

Most (but not all) studies suggest that a prior history of peptic ulcer increases the risk of ulcer complications whether patients do or do not use NSAIDS. Moreover, risk remains high, at least for endoscopic ulcers, even when patients stop taking NSAIDs. ${ }^{89}$ As this persisting risk appears to affect both $H$ pylori negative and positive patients, and to be site preferential, ${ }^{90} 91$ it is likely to reflect some local vulnerability of the mucosa at the site of prior ulceration.

Magnification of a high background risk in patients with a past ulcer history who use NSAIDs results in particularly high rates of ulcer complications. ${ }^{92-94}$ Consequently, risk reductions in such patients switched from a non-selective NSAID to a COX-2 inhibitor, such as rofecoxib (by 8.8 events per 100 patient years in VIGOR) are much greater than in those without prior ulceration (by 2 events per 100 patient years), ${ }^{54}$ with similar results for celecoxib in CLASS..$^{95}$ The substantial risk reduction associated with a switch to a COX-2 inhibitor in the ulcer prone, with a low NNT, makes their use practical and economically attractive.

\section{"The substantial risk reduction associated with a switch to a COX-2 inhibitor in the ulcer prone, with a low NNT, makes their use practical and economically attractive"}

However, many would regard as unacceptable the high residual risk after switching to a COX-2 inhibitor (which in VIGOR was 10 events per 100 patient years). ${ }^{96}$ This residual risk seems likely, but not certain, to reflect true residual risk rather than any remaining gastrotoxicity of COX-2 inhibitors. Co-prescription of a PPI would seem an appropriate strategy in patients with a past ulcer history as PPIs can influence not only NSAID associated risk but also that attributable to the residual influence of previous ulceration. In endoscopy studies, omeprazole reduced ulcer recurrence by $78 \%$ in those without $^{84}$ and $64 \%$ in those with ulcers ${ }^{97}$ initially, compared with $54 \%$ for perforation, ulcer, and bleeds with rofecoxib 50 mg versus ibuprofen $2400 \mathrm{mg}$ (all patients). Results with lansoprazole and pantoprazole have been similar to those seen with omeprazole ${ }^{78-80}$ and omeprazole itself has been shown to reduce ulcer rebleeding fourfold ${ }^{81}$ Again, direct comparison of the occurrence rates of symptomatic/complicated ulcer in patients treated with low dose non-selective NSAIDs under PPI protection with those receiving COX-2 inhibitors (alone and combined with a PPI) would be of considerable clinical interest and is a strategy some might prefer on current limited evidence.

\section{Older patients}

Risks of ulcer and ulcer complications increase with age in individuals who do not use NSAIDs. These raised risks may reflect the cohort pattern of ulcer morbidity and mortality observed since the second half of the 19th century, ${ }^{97}$ and now in its decline, and itself may be partly explained by an increased prevalence of $H$ pylori currently seen in older people. Other factors, including an accumulated history of subclinical ulcers and reduced mucosal integrity due to vascular disease, may also be important. NSAIDs consistently magnify background risk by some fourfold, regardless of age, so that the proportion of disease attributable to NSAIDs remains constant. It was therefore predictable that substitution of a COX-2 selective inhibitor for standard NSAID would result in marked reductions in the numbers affected, but also leave substantial residual risk. Given the uncertainty about the mechanism(s) that leads to increased risk in the elderly, arguments can be made for using COX-2 inhibitors, or for using non-selective NSAIDs with PPIs. Sound comparative evidence of overall gastrointestinal and non-gastrointestinal safety in this group is needed.

\section{Patients requiring high doses of NSAIDs}

Increasing NSAID dosage within the accepted ranges approximately triples the risk of ulcer complications (table 2$)^{41}{ }^{88} \mathrm{By}$ contrast, full dose coxibs possess equivalent anti- inflammatory and analgesic power, and available evidence suggests that they should not increase gastrointestinal risk although risks associated with fluid retention may rise. ${ }^{11}$

\section{Patients requiring corticosteroids}

Correct management is difficult to identify unequivocally as evidence conflicts about the effect of corticosteroids on the risk of ulcer disease. ${ }^{87}$ 99-102 If, as some studies suggest, the effect of corticosteroids is to act only as an NSAID specific risk magnifier, ${ }^{100} 102$ particular benefit would be anticipated with COX-2 inhibitors, and there was some evidence for this in the VIGOR study ${ }^{96} 103$ Other studies however suggest that corticosteroids also increase risk in non-NSAID users ${ }^{87}{ }^{99}$ making vigorous prophylactic strategies possibly more appropriate for those on high dose corticosteroids with multiple current diseases.

\section{$H$ pylori positive patients}

The interaction between $H$ pylori and NSAIDs is controversial, with some reports suggesting that infection raises the chances of NSAID associated ulcer, ${ }^{104}$ others the reverse. ${ }^{105}{ }^{106}$ Regardless of such controversy, when patients use COX-2 inhibitors, $H$ pylori would be expected to remain a source of continuing ulcer risk, requiring eradication in appropriate patients. Although there are no trials, this approach is supported by data from the VIGOR study where the residual risk of ulcers in patients taking rofecoxib was approximately doubled in $H$ pylori infected compared with non-infected individuals.. ${ }^{96} 103$

\section{Patients with cardiovascular disease}

These patients currently pose the greatest intellectual and therapeutic challenge in this area. Claimed associations of ulcer bleeding with cardiovascular disease, or its treatment, are common. In assessing such claims, allowance has to be made for concurrent aspirin and anticoagulant use and for concurrent disease. A weakly significant association of ulcer bleeding with prior cardiovascular disease was found in the MUCOSA study. ${ }^{77}$ In a case control study an odds ratio of 5.9 (2.3-13.1) for the influence of cardiovascular disease appeared independent of aspirin and anticoagulant use. ${ }^{87}$ Thus arthritic patients with heart disease may have multiple risks —of ulcer complications both from cardiovascular disease and from aspirin use, along with an enhanced rate of hypertension from use of NSAIDs or COX-2 inhibitors (although a suggested association with calcium channel blockade ${ }^{107}$ has not been confirmed, ${ }^{87}$ and nitrates claimed to protect or to have little effect). ${ }^{108}$ 
"Claimed associations of ulcer bleeding with cardiovascular disease, or its treatment, are common"

Management of such patients should start from assessment of the net value of aspirin. This is clear cut for secondary prophylaxis and for some high risk groups ${ }^{29}{ }^{30}$ but more widespread use may cause more harm than good. ${ }^{29}$ Secondly, for those who need aspirin, doses above $100 \mathrm{mg}$ daily are not evidence based and result in increased risk of ulcer bleeding ${ }^{29}$ (a meta-analysis suggesting no dose dependence ${ }^{109}$ seems flawed because it compared high dose studies in the 1970s with low dose studies in the 1990s when inclusion criteria differed and reporting of complications was likely to have been more rigorous). If a patient needs aspirin, recent data on the interaction with ibuprofen ${ }^{40}$ suggests it is unsafe to assume that aspirin would protect against coronary thrombosis in the presence of this drug. Such a patient needing anti-inflammatory medication might benefit from a selective COX-2 inhibitor, not for its gastroprotective effects but for its permissive cardiovascular benefits in allowing aspirin to continue to be effective. Because this is as yet speculative, direct data on clinical end points are needed.

As aspirin itself increases the risk of ulcer bleeding, whether or not patients use COX-2 inhibitors, those that are at high risk from such aspirin use (for example, following an ulcer bleed) would logically be managed under the protection of a PPI. Abandoning aspirin following an ulcer bleed in a patient with significant coronary instability would run the risk of precipitating vascular events during hypotension following haemorrhage, or as a consequence of the bleeding induced hypercoagulable state. The chances of cardiovascular death are overall many times greater than those of ulcer death. Equally, switching to a non- aspirin antiplatelet agent seems both optimistic in discounting a role for haemostasis in ulcer bleeding and contentious, given that associations with gastrointestinal bleeding have been reported. ${ }^{110} 111$

On the other hand, until recently, there was little direct evidence for a protective effect of PPIs on the risk of ulcer bleeding in patients taking cardioprotective doses of aspirin. Abundant endoscopic data showed that PPIs protected against aspirin induced injury up to one month, but longer term patient studies with doses of aspirin $\leqslant 325 \mathrm{mg}$ were lacking. Recently published data have clarified the matter by showing a substantial reduction in ulcer rebleeding in users of aspirin $100 \mathrm{mg}$ treated with lansoprazole $30 \mathrm{mg}$ compared with placebo, following $\mathrm{H}$ pylori eradication in all. ${ }^{82}$

\section{Patients with coagulation defects or on anticoagulants} Use of anticoagulants results in an increase in ulcer bleeding in the absence of NSAID use, a similar proportionate magnification with NSAIDs, and a consequential high absolute excess risk in these circumstances. ${ }^{8712}$ Consequently, prescribers tend to avoid NSAIDs in patients taking anticoagulants or with coagulation deficiencies, despite a need for pain relief in, for example, patients with haemophiliac arthropathy. Although there are no data, lack of any antiplatelet effect is sufficient justification to use COX-2 inhibitors in these patients although monitoring prothrombin time is desirable. ${ }^{113}$

\section{CONCLUSIONS}

It is likely that an overall reduction in NSAID toxicity will only be achieved by applying different strategies to different patients. There are sufficient data to make a best guess at what these should be. However, as we have indicated throughout this article, there is an outstanding research agenda involving direct comparison of strategies by subgroup. These could be amalgamated into a comparison of subgroup optimised management with cruder strategies that would need research council support, given that such an approach is unlikely to be forthcoming from the pharmaceutical industry.

\section{ACKNOWLEDGEMENTS}

We thank Miss Laura Garratt for her assistance with the production of this manuscript.

\section{Authors' affiliations}

C J Hawkey, Division of Gastroenterology, Queen's Medical Centre, University Hospital Nottingham, Nottingham, UK

M J S Langman, Department of Medicine, Queen Elizabeth Hospital, Birmingham B 12 2TH, UK

\section{REFERENCES}

1 Rockall TA, Logan RF, Devlin HB, et al. Incidence of and mortality from acute upper gastrointestinal haemorrhage in the United Kingdom. Steering Committee and members of the National Audit of Acute Upper Gastrointestinal Haemorrhage. BM 1995;311:222-6.

2 Langman MJS. Ulcer complications associated with anti-inflammatory drug use. What is the extent of the disease burden? Pharmacoepidemiol Drug Safety $2001 ; 10: 13-19$.

3 Hawkey CJ, Cullen DJE, Greenwood DC, et al. Prescribing of nonsteroidal anti- inflammatory drugs in general practice: Determinants and consequences. Aliment Pharmacol Ther 1997;11:293-8.

4 Mortality statistics: general. Series DH1. No. 31. Review of the Registrar General on deaths in England and Wales, 1998. Nationa Statistics (C) Crown Copyright 2001

5 Tramer MR, Moore RA, Reynolds DJM, et al. Quantitative estimation of rare adverse events which follow a biological progression: A new model applied to chronic NSAID use. Pain 2000;85:169-82.

6 Smalley WE, Ray WA, Daugherty JR, et al. Nonsteroidal anti-inflammatory drugs and the incidence of hospitalizations for peptic ulcer disease in elderly persons. Am J Epidemiol 1995;141:539-45.

7 Singh G. Recent considerations in nonsteroidal anti-inflammatory drug gastropathy. Am J Med 1998;105:31-8S.

8 Wolfe MM, Lichtenstein DR, Singh G. Gastrointestinal toxicity of nonsteroidal antiinflammatory drugs. N Engl J Med 1999;340:1888-99.

9 Sonnenberg A. Peptic ulcer. In: Everhart JE, ed, Digestive Disease in the United States: Epidemiology and impact. Bethesda: National Institutes of Health, 1994

10 Belton KJ, Lewis SC, Matthews JNS, et al. Systematic overview of upper gastrointestinal haemorrhage associated with non-steroidal anti-inflammatory drugs. In: Fracchia GN, ed. Prespectives in anti-inflammatory drugs. In: Fracchia GN, ed. Prespectives in
pharmacotoxicology and pharmacovigilance. Brussels: IOS Press, 1994.

11 Bombardier C, Laine L, Reicin A, et al. Comparison of upper gastrointestinal toxicity of rofecoxib and naproxen in patients with rheumatoid arthritis. VIGOR Study Group. N Engl J Med 2000;343: 1520-8.

12 Silverstein FE, Faich G, Goldstein JL, et al. Gastrointestinal toxicity with celecoxib vs nonsteroidal anti-inflammatory drugs for osteoarthritis and rheumatoid arthritis: the CLASS study: A randomized controlled trial. Celecoxib Long-term Arthritis Safety Study. JAMA 2000;284:1247-55.

13 Berg Hrachovec J, Mora M. Reporting of 6 -month vs. 12 -month date in a clinical trial of celecoxib. JAMA 2002;286:2398.

14 Wright JM, Perry TP, Bassett KL, et al. Reporting of 6-month vs. 12-month date in a clinical trial of celecoxib. JAMA 2002;286:2399.

15 Silverstein F, Simon L, Faich G. Reporting of 6-month vs. 12-month date in a clinical trial of celecoxib. JAMA 2002;286:2399.

16 Langman MJ, Morgan L, Worrall A. Use of anti-inflammatory drugs by patients admitted with small or large bowel perforations and haemorrhage. BM 1985;290:347-9.

17 Hawkey CJ. Nonsteroidal anti-inflammatory drug gastropathy. Gastroenterology 2000;1 19:521-35.

18 Catella-Lawson F, McAdam B, Morrison BW, et al. Effects of specific inhibition of cyclooxygenase- 2 on sodium balance, hemodynamics, and vasoactive eicosanoids. J Pharmacol Exp Ther 1999;289:735-41.

19 Rossat J, Maillard M, Nussberger J, et al. Renal effects of selective cyclooxygenase-2 inhibition in normotensive salt-depleted subjects. Clin Pharmacol Ther 1999:66:76-84.

20 Whelton A, Schulman G, Wallemark C, et al. Effects of celecoxib and naproxen on renal function in the elderly. Arch Intern Med 2000; 160: 1465-70.

21 Brater DC, Harris C, Redfern JS, et al. Renal effects of COX-2-selective inhibitors. Am J Nephrol 2001:21:1-15.

22 Swan SK, Rudy DW, Lasseter KC, et al. Effect of cyclooxygenase-2 inhibition on renal function in elderly persons receiving a low-salt diet. A randomized, controlled trial. Ann Intern Med 2000;133:1-9.

23 Mukheriee D, Nissen SE, Topol EJ. Risk of cardiovascular events associated with selective COX-2 inhibitors. JAMA 2001;286:954-9.

24 Patrono C, Patrignani P, Garcia Rodriguez LA.

Cyclooxygenase-selective inhibition of prostanoid formation: transducing biochemical selectivity into clinical read-outs. J Clin Invest 2001; 108:7-13.

25 Pope JE, Anderson JJ, Felson DT. A meta-analysis of the effects of nonsteroidal anti- inflammatory drugs on blood pressure. Arch Intern Med 1993;153:477-84

26 Johnson AG, Nguyen TV, Day RO. Do nonsteroidal anti-inflammatory drugs affect blood pressure? A meta-analysis. Ann Intern Med 1994;121:289-300.

27 MacMahon S, Peto R, Cutler J, et al. Blood pressure, stroke, and coronary heart disease. Part 1, Prolonged differences in blood pressure: 
prospective observational studies corrected for the regression dilution bias Lancet 1990:335:765-74.

28 Page J, Henry D. Consumption of NSAIDs and the development of congestive heart failure in elderly patients: an underrecognized public health problem. Arch Intern Med 2000;160:777-84

29 Patrono C, Coller B, Dalen JE, et al. Platelet-active drugs: The relationships among dose, effectiveness, and side effects. Chest 1998;114(suppl 5):470-88S

30 Collaboration AT. Collaborative meta-analysis of randomised trials of antiplatelet therapy for prevention of death, myocardial infarction, and stroke in high risk patients. BN 2002;324:71-86

31 McAdam BF, Catella-Lawson F, Mardini IA, et al. Systemic biosynthesis of prostacyclin by cyclooxygenase (COX)-2: The human pharmacology of a selective inhibitor of COX-2. Proc Natl Acad Sci U S A 1999; $96: 272-7$

32 Jick SS. The risk of gastrointestinal bleed, myocardial infarction, and newly diagnosed hypertension in users of meloxicam, diclofenac, naproxen, and piroxicam. Pharmacotherapy 2000;20:741-4.

33 Brochier ML. Evaluation of flurbiprofen for prevention of reinfarction and reocclusion after successful thrombolysis or angioplasty in acute myocardial infarction. Eur Heart J 1993;14:951-7.

34 Garcia Rodriguez LA, Varas C, Patrono C. Differential effects of aspirin and nonsteroidal anti-inflammatory drugs in the primary prevention of myocardial infarction in postmenopausal women. Epidemiology 2000; 11:382-7.

35 Ray WA, Stein $M$, Hall K, et al. Non-steroidal anti-inflammatory drugs and risk of serious coronary heart disease: an observational cohort study. Lancet 2002;359:1 18-123.

36 Dalen JE. Selective COX-2 inhibitors, NSAIDs, aspirin, and myocardial infarction. Arch Intern Med 2002:162:1091-2.

37 Solomon DH, Glynn RJ, Levin RI, et al. Nonsteroidal anti-inflammatory drug use and acute myocardial infarction. Arch Intern Med 2002; 127: 1099-104

38 Watson DJ, Rhodes T, Cai B, et al. Lower risk of thromboembolic cardiovascular events with naproxen among patients with rheumatoid arthritis. Arch Intern Med 2002;162:1 105-110.

39 Rahme E, Pilote L, LeLorier J. Association between naproxen use and protection against acute myocardial infarction. Arch Intern Med 2002; 162:1111-15.

40 FitzGerald GA, Patrono $C$. The coxibs, selective inhibitors of cyclooxygenase-2. N Engl J Med 2001;345:433-42.

41 Henry D, Lim L-Y, Garcia Rodriguez LA, et al. Variability in risk of gastrointestinal complications with individual non-steroidal anti-inflammatory drugs: Results of a collaborative meta-analysis. BM 1996:312:1563-6.

42 Guidelines: ACoRSoO. Recommendations for the Medical Management of Osteoarthritis of the Hip and Knee. Arthritis Rheum 2000;43:190515.

43 Jawad AS. EULAR recommendations for the management of knee osteoarthritis. Ann Rheum Dis 2001;60:540.

44 National Institute of Clinical Excellence. Guidance on the use of cyclo-oxygenase (Cox) II selective inhibitors, celecoxib, rofecoxib, meloxicam and etodolac for osteoarthritis and rheumatoid arthritis. London: Technology Appraisal Guidance-No. 27 Government publication, 2001

45 Laine $\mathrm{L}$, Harper $\mathrm{S}$, Simon $\mathrm{T}$, et al. A randomized trial comparing the effect of rofecoxib, a cyclooxygenase 2-specific inhibitor, with that of ibuprofen on the gastroduodenal mucosa of patients with osteoarthritis. Gastroenterology 1999;117:776-83.

46 Hawkey C, Laine L, Simon T, et al. Comparison of the effect of rofecoxib (a cyclooxygenase 2 inhibitor), ibuprofen, and placebo on the gastroduodenal mucosa of patients with osteoarthritis: A randomized, double-blind, placebo-controlled trial. Arthritis Rheum 2000;43:370-7.

47 Collins R, Peto R, Macmahon S, et al. Blood pressure, stroke and coronary heart disease. Part 2. Short term reductions in blood pressure: overview of randomized drug trials in their epidemiological context. Lancet 1990;335:827-38

48 Emery $\mathbf{P}$, Zeidler $\mathrm{H}$, Kvien TK, et al. Celecoxib versus diclofenac in long-term management of rheumatoid arthritis: Randomised double-blind comparison. Lancet 1999:354:2106-11

49 Simon LS, Weaver AL, Graham DY, et al. Anti-inflammatory and upper gastrointestinal effects of celecoxib in rheumatoid arthritis: A randomized controlled trial. JAMA 1999;282:1921-8.

50 Goldstein JL, Correa P, Zhao WW, et al. Reduced incidence of gastroduodenal ulcers with celecoxib, a novel cyclooxygenase-2 inhibitor, compared to naproxen in patients with arthritis. Am J Gastroenterol 2001;96:1019-27.

51 Agrawal N, Paperiello B, Zhao WW, et al. Supratherapeutic Doses of valdecoxib have a reduced incidence of gastroduodenal ulcers compared with conventional therapeutic doses of naproxen in osteoarthritis and rheumatoid arthritis patients. Arthritis Rheum 2001;44(suppl 9):A1917

52 Goldstein JL, Fakouhi KM, Zhao WW, et al. Reduced incidence of gastroduodenal ulcers with valdecoxib compared to ibuprofen and diclofenac in patients with osteoarthritis: a multicentre trial. Gastroenterology 2001;120(suppl 5):A597

53 Langman MJ, Jensen DM, Watson DJ, et al. Adverse upper gastrointestinal effects of rofecoxib compared with NSAIDs. JAMA 1999:282:1929-33

54 Laine L. Stratifying the risk of clinical upper GI events in NSAID users: results from a double-blind outcomes study. Gastroenterology $2001 ; 120:$ A552.
55 Schwartz JI, Malice MP, Kalyani R, et al. Comparison of rofecoxib, celecoxib, and naproxen on blood pressure in elderly volunteers. Clin Pharmacol Ther 2002;71: 7-8.

56 Whelton A, Fort JG, Puma JA, et al. Cyclooxygenase-2-specific inhibitors and cardiorenal function: a randomized, controlled trial of celecoxib and rofecoxib in older hypertensive osteoarthritis patients. (Erratum appears in Am J Ther $2001 ; 8: 220)$. Am J Ther 2001;8:85-95.

57 site FCw. http://www.fda.gov/cder/foi/label/1998/20998lbl.pdf, 1999

58 FDA Rofecoxib website: http://www.fda.gov/ohrms/dockets/and colleagues/01/slides/3677s2_01_sponsor.pdf, 2001

59 Konstam MA, Weir MR, Reicin A, et al. Cardiovascular thrombotic events in controlled, clinical trials of rofecoxib. Circulation 2001; 104:2808-13

60 Wight N, Gottesdiener K, Garlick NM, et al. Rofecoxib, A COX-2 inhibitor, does not inhibit human gastric mucosal prostaglandin production. Gastroenterology 2001;120:867-73.

61 Josefson D. FDA warns Merck over its promotion of rofecoxib. BM 2001;323:767.

62 Wallace JL, McKnight W, Reuter BK, et al. NSAID-induced gastric damage in rats: requirement for inhibition of both cyclooxygenase 1 and 2. Gastroenterology 2000;119:706-14.

63 Catella-Lawson F, Reilly MP, Kapoor SC, et al. Cyclooxygenase inhibitiors and the antiplatelet effects of aspirin. N Engl J Med 2001;345:1809-17.

64 Whittle BJ, Vane JR. A biochemical basis for the gastrointestinal toxicity of non- steroid antirheumatoid drugs. Arch Toxicol Suppl 1984;7:315-22.

65 Botting R. Paracetamol-inhibitable COX-2. J Physiol Pharmacol 2000:51:609-18.

66 Coggon D, Langman M, Spiegelhalter D. Aspirin, paracetamol, and haematemesis and melaena. Gut 1982;23:340-4.

67 Mclntosh JH, Fung CS, Berry G, et al. Smoking, nonsteroidal anti-inflammatory drugs, and acetaminophen in gastric ulcer. A study of associations and of the effects of previous diagnosis on exposure patterns. Am J Epidemiol 1988:128:761-70.

68 Garcia Rodriguez LA, Hernandez-Diaz S. Relative risk of upper gastrointestinal complications among users of acetaminophen and nonsteroidal anti-inflammatory drugs. Epidemiology 2001;12:570-6.

69 Lewis SC, Langman NS, Laporte JR, et al. Dose-response relationships between individual non-aspirin non-steroidal anti-inflammatory drugs (NANSAIDs) and serious upper gastrointestinal bleeding: a meta-analysis based on individual patient data. Br J Clin Pharmacol 2002;54:320-6.

70 Day RO, Graham GG, Williams KM, et al. Clinical pharmacology of non-steroidal anti-inflammatory drugs. Pharmacol Ther 1987;33:383-433

71 Brooks PM, Day RO. Nonsteroidal antiinflammatory drugs-differences and similarities. N Engl J Med 1991;324:1716-25.

72 Juni P, Rutjes AWS, Dieppe PA. Gastrointestinal ulcer complications: Are selective COX-2 inhibitors superior to traditional NSAIDs? BM 2002;324: 1287-8

73 Brater DC, McCarthy DM, Fries JF. Effects of nonsteroidal anti-inflammatory drugs on renal function: Focus on cyclooxygenase-2-selective inhibition. Am J Med 1999;107/supp 1):65-71S.

74 Rossi AC, Hsu JP, Faich GA. Ulcerogenicity of piroxicam: an analysis of spontaneously reported data. BM 1987;294: 147-50.

75 Langman MJ, Weil J, Wainwright $P$, et al. Risks of bleeding peptic ulce associated with individual non-steroidal anti-inflammatory drugs. Lancet 1994;343:1075-8

76 Koch M, Dezi A, Ferrario F, et al. Prevention of nonsteroidal anti-inflammatory drug- induced gastrointestinal mucosal injury: A meta-analysis of randomized controlled clinical trials. Arch Intern Med 1996:156:2321-32.

77 Silverstein FE, Graham DY, Senior JR, et al. Misoprostol reduces serious gastrointestinal complications in patients with rheumatoid arthritis receiving nonsteroidal anti-inflammatory drugs. A randomized, double-blind, placebo-controlled trial. Ann Intern Med 1995; 123:241-9.

78 Yeomans ND, Tulassay Z, Juhasz L, et al. A comparison of omeprazole with ranitidine for ulcers associated with nonsteroidal antiinflammatory drugs. Acid Suppression Trial: Ranitidine versus Omeprazole for NSAID-associated Ulcer Treatment (ASTRONAUT) Study Group. N Engl J Med 1998;338:719-26.

79 Hawkey CJ, Karrasch JA, Szczepanski L, et al. Omeprazole compared with misoprostol for ulcers associated with nonsteroidal antiinflammatory drugs. N Engl J Med 1998;338:727-34.

80 Agrawal NM, Campbell DR, Safdi MA, et al. Superiority of lansoprazole vs ranitidine in healing nonsteroidal anti-inflammatory drug-associated gastric ulcers: results of a double-blind, randomized, multicenter study. NSAID-Associated Gastric Ulcer Study Group. Arch Intern Med 2000;160:1455-61.

81 Chan FKL, Chung SCS, Suen RN, et al. Preventing recurrent upper gastrointestinal bleeding in patients with Helicobacter pylori infection who are taking low-dose aspirin or naproxen. N Engl J Med 2001;344:967-73

82 Lai K-C, Lam S-K, Chu K-M, et al. H. pylori eradication vs. Combined proton pump inhibitor and $H$. pylori eradication in the prevention of recurrent peptic ulcer complications in high-risk patients receiving low-dose aspirin. Gastroenterology 2001;120(suppl 5):A550.

83 Ekstrom P, Carling L, Wetterhus S, et al. Prevention of peptic ulcer and dyspeptic symptoms with omeprazole in patients receiving continuous 
non-steroidal anti-inflammatory drug therapy. A nordic multicentre study. Scand J Gastroenterol 1996:31:753-8.

84 Cullen D, Bardhan KD, Eisner M, et al. Primary gastroduodena prophylaxis with omeprazole for non-steroidal anti-inflammatory drug users. Aliment Pharmacol Ther 1998;12:135-40.

85 Taha AS, Hudson N, Hawkey CJ, et al. Famotidine for the prevention of gastric and duodenal ulcers caused by nonsteroidal antiinflammatory drugs. N Engl J Med 1996;334:1435-9.

86 Singh G Rosen Ramey D. NSAID induced gastrointestinal complications: the ARAMIS perspective--1997. Arthritis, Rheumatism, and Aging Medical Information System. J Rheumatol Suppl 1998;51:8-16.

87 Weil J, Langman M, Wainwright P, et al. Peptic ulcer bleeding: accessory risk factors and interactions with non-steroidal anti-inflammatory drugs. Gut 2000;46:27-31.

88 Langman MJS, Weil J, Wainwright $P$, et al. Risks of bleeding peptic ulcer associate with individual non-steroidal anti-inflammatory drugs. Lancet 1994;343:1075-8.

89 Hawkey CJ, Laine L, Harper SE, et al. Influence of risk factors on endoscopic and clinical ulcers in patients taking rofecoxib or ibuprofen in two randomized controlled trials. Aliment Pharmacol The 2001:15:1593-601.

90 Hawkey CJ, Tulassay Z, Szczepanski L, et al. Randomised controlled trial of Helicobacter pylori eradication in patients on non-steroidal anti-inflammatory drugs: HELP NSAIDs study. Lancet 1998;352:101621.

91 Hawkey CJ, Naesdal J, Wilson I, et al. Scars not bugs: Relative contribution of mucosal injury and Helicobacter pylori in the development of gastroduodenal lesions in patients taking non-steroidal anti-inflammatory drugs. Gut 2002;51:336-43

92 Gabriel SE, Jaakkimainen L, Bombardier C. Risk for serious gastrointestinal complications related to use of nonsteroidal anti-inflammatory drugs: A meta-analysis. Ann Intern Med $1991 ; 115: 787-96$

93 Hawkey CJ, Snowden JA, Lobo A, et al. Stem cell transplantation for inflammatory bowel disease: practical and ethical issues. Gut 2000;46:869-72

94 Garcia Rodriguez LA, Williams R, Derby LE, et al. Acute liver injury associated with nonsteroidal anti-inflammatory drugs and the role of risk factors. Arch Intern Med 1994;154:311-6.

95 FDA Celecoxib website: http://www.fda.gov/ohrms/dockets/ac/01/ slides/3677s 101 sponsor.pdf, 2001.

96 Laine L, Hawkey CJ, Bombardier C, et al. Stratifying the Risk of Clinical Upper GI Events in NSAID Users: Results froma Double-Blind Outcomes Study. Gastroenterology 2001 ; (suppl 5):A552.

97 Hawkey CJ, Karrasch JA, Szczepanski L, et al. Omeprazole compared with misoprostol for ulcers associated with nonsteroidal antiinflammatory drugs. Omeprazole versus Misoprostol for NSAID-induced Ulcer Management (OMNIUM) Study Group. N Engl J Med 1998;338:727-34

98 Susser S. Causes of peptic ulcer: a selective epidemiological review. J Chronic Dis 1967;20:435-56.

99 Messer J, Reitman D, Sacks HS, et al. Association of adrenocorticosteroid therapy and peptic-ulcer disease. N Engl J Med 1983;309:21-4.

100 Piper JM, Ray WA, Daugherty JR, et al. Corticosteroid use and peptic ulcer disease: Role of nonsteroidal anti-inflammatory drugs. Ann Intern Med 1991;114:735-40.

101 Holvoet J, Terriere L, Van Hee W, et al. Relation of upper gastrointestinal bleeding to non-steroidal anti-inflammatory drugs and aspirin: A case-control study. Gut 1991;32:730-4.

102 Hochain P, Berkelmans I, Czernichow P, et al. Which patients taking non-aspirin non-steroidal anti-inflammatory drugs bleed? A case-control study. Eur J Gastroenterol Hepatol 1995;7:419-26.

03 Merck data presented to FDA Ft.

104 Huang J-Q, Sridhar S, Hunt RH. Role of Helicobacter pylori infection and non- steroidal anti-inflammatory drugs in peptic ulcer disease: meta analysis. Lancet 2002;359:14-22.

105 Hawkey CJ. Personal review: Helicobacter pylori, NSAIDs and cognitive dissonance. Aliment Pharmacol Ther 1999.13:695-702.

106 Yeomans ND, Garas G, Hawkey CJ. The nonsteroidal anti-inflammatory drugs controversy. Gastroenterol Clin North Am 2000;29:791-805.

107 Garcia Rodriguez LA, Cattaruzzi C, Troncon MG, et al. Risk of hospitalisation for upper gastrointestinal track bleeding associated with ketorolac, other nonsteroidal anti-inflammatory drugs, calcium antagonists, and other antihypertensive drugs. Arch Intern med $1998 ; 158: 33-9$.

108 Lanas A, Bajador E, Serrano P, et al. Nitrovasodilators, low-dose aspirin, other nonsteroidal antiinflammatory drugs, and the risk of upper gastrointestinal bleeding. N Engl J Med 2000;343:834-9.

109 Derry S, Loke KY. Risk of gastrointestinal haemorrhage with long-term use of aspirin:a meta analysis. BM 2000;321:1183-7.

110 Anonymous. A randomised, blinded, trial of clopidogrel versus aspirin in patients at risk of ischaemic events (CAPRIE). CAPRIE Steering Committee. Lancet 1996;348:1329-39.

111 van Hecken A, Depre M, Wynants K, et al. Effect of clopidogrel on naproxen- induced gastrointestinal blood loss in healthy volunteers. Drug Metab Drug Interact 1998;14:193-205.

112 Shorr RI, Ray WA, Daugherty JR, et al. Concurrent use of nonsteroidal anti- inflammatory drugs and oral anticoagulants places elderly persons at high risk for hemorrhagic peptic ulcer disease. Arch Intern Med 1993; 153:1665-70.

113 Schwartz JI, De Smet M, Larson PJ, et al. Effect of rofecoxib on the pharmacokinetics of digoxin in healthy volunteers. J Clin Pharmacol 2001;41:107-12. 